\title{
Pengaruh User Experience terhadap Kepuasan Konsumen Generasi Z pada Sistem Pemesanan Mcdelivery Mobile Application di Jawa Barat
}

\section{Effects of User Experience on Z Generation towards Consumer Satisfaction in the McDelivery Mobile Application Ordering System in West Java}

Fadil Saadillah $^{1}$, Edward Halomoan Siregar ${ }^{1 *}$

1) Departemen Manajemen, Fakultas Ekonomi dan Manajemen, IPB Kampus Dramaga Bogor 16680

\begin{abstract}
Today the internet has made such a large contribution in which around 132,7 million peoples in Indonesia use the internet actively and makes Indonesia becomes a country with the largest consumers of virtual transaction in Southeast Asia. McDelivery Mobile Application is one of long distance fast food ordering applications which is able to compete with the similar applications and have to achieve customer retention target. The method used is non probability sampling with snowball sampling technique with 100 respondents which is analyzed by Structural Equation Modeling (SEM) with the Partial Least Squares (PLS) approach. As the result, only the dimensions of Novelty and Stimulation with T-statistics amounted to 2,612 and 3,903(> 1,96) which had a significant effect, because they met the requirements of the T-statistic value greater than the T-table (1,96 at the real level of 0,05).
\end{abstract}

Keywords: consumer Satisfaction, SEM-PLS, User Experience.

\begin{abstract}
ABSTRAK
Internet telah memberikan kontribusi besar dimana sekitar 132,7 juta orang secara aktif menggunakan internet di Indonesia menjadikan Indonesia sebagai negara dengan konsumen jual beli virtual terbanyak di Asia Tenggara. McDelivery Mobile Application merupakan salah satu aplikasi pemesanan makanan cepat saji jarak jauh yang mampu bertahan di tengah persaingan aplikasi sejenisnya sehingga harus mencapai target terbentuknya customer retention. Metode yang digunakan ialah non probability sampling dengan teknik snowball sampling dengan jumlah sampel 100 responden dan diolah menggunakan Structural Equation Modelling (SEM) dengan pendekatan Partial Least Squares (PLS). Hasil penelitian menunjukkan bahwa hanya dimensi Kebaruan dan Stimulasi dengan T-statistik sebesar masingmasing 2,612 dan 3,903 (>1,96) yang mempunyai pengaruh signifikan, karena memenuhi syarat nilai T-statistik lebih besar dari T-tabel $(1,96$ pada taraf nyata 0,05$)$.
\end{abstract}

Kata Kunci: kepuasan Konsumen, SEM-PLS, User Experience.

*Corresponding author

Alamat e-mail: edward@apps.ipb.ac.id 


\section{PENDAHULUAN}

Dewasa ini perkembangan teknologi informasi dan komunikasi semakin mengalami kemajuan terutama dalam bidang komunikasi dan interaksi masyarakat. Internet telah memberikan kontribusi yang demikian besar terutama bagi perusahaan atau industri maupun pemerintah. Hasil survei yang dilakukan oleh Asosiasi Penyelenggara Jasa Internet Indonesia (APJII) pada tahun 2016 dimana hasilnya sekitar 51,8 persen atau sekitar 132,7 juta orang secara aktif menggunakan internet. Hal ini berpengaruh terhadap peningkatan penggunaan telpon seluler yang telah dilengkapi dengan akses layanan internet (Smartphone) di Indonesia. Selanjutnya diramalkan bahwa sampai tahun 2019 penggunaan smartphone di Indonesia akan semakin meningkat ditunjukkan melalui hasil data dari Katadata.co.id pada Gambar 1.

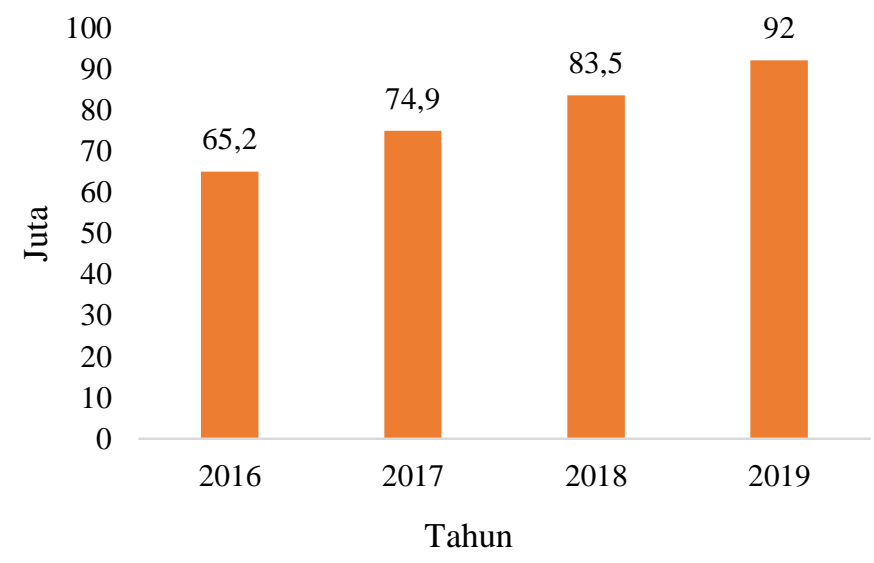

Gambar 1. Pengguna smartphone di Indonesia 2016-2019 Sumber: Katadata.co.id (Data diolah 2019)

Pada tahun 2017 berdasarkan riset yang dilakukan oleh Asosiasi Penyelenggara Jasa Internet Indonesia (APJII), menemukan bahwa hasil survei dari 143,26 juta penduduk Indonesia berdasarkan usia menunjukkan bahwa pengguna dengan usia 19-34 tahun mendominasi penggunaan internet sebesar 49,52 persen. Hal ini menjelaskan bahwa pengguna internet Indonesia didominasi oleh remaja hingga orang dewasa, seperti dapat dilihat pada Gambar 2.

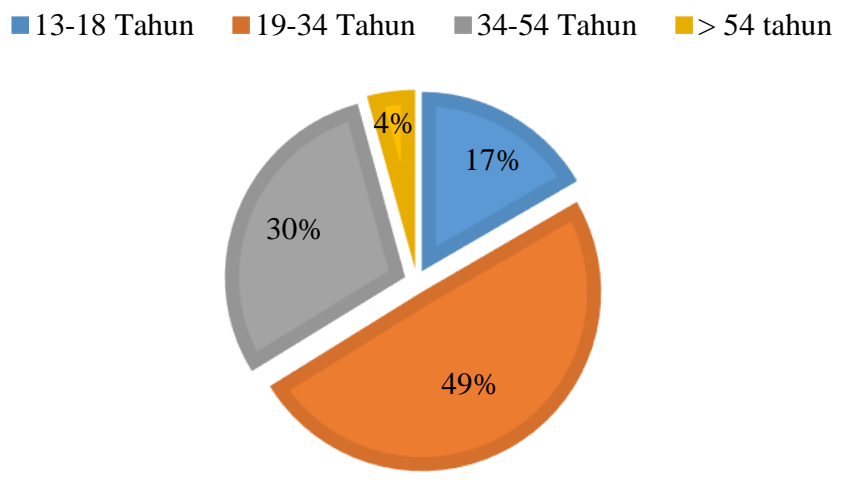

Jurnal Manajemen dan Organisasi

(JMO),

Vol. 10 No. 2,

Agustus 2019,
Hal. 92-101
Gambar 2. Komposisi pengguna internet Indonesia berdasarkan usia Sumber: Asosiasi Penyelenggara Jasa Internet Indonesia (Data diolah 2019)

Sementara itu untuk data khusus pulau Jawa juga mengalami peningkatan yang cukup signifikan. Berdasarkan riset yang dilakukan Badan Pusat Statistika (BPS) tentang persentase penduduk yang memiliki atau menguasai telepon seluler di perkotaan terlihat bahwa Jawa barat menempati posisi ke 2 setelah DKI Jakarta. Hal ini dapat dilihat pada Tabel 1. 


\begin{tabular}{cccccc}
\hline \multirow{2}{*}{ Provinsi } & \multicolumn{5}{c}{ Persentase Penduduk yang Memiliki/Menguasai Telepon } \\
& \multicolumn{5}{c}{ Seluler Menurut Provinsi dan Klasifikasi Daerah Perkotaan } \\
\hline DKI JAKARTA & 2012 & 2013 & 2014 & 2015 & 2016 \\
JAWA BARAT & 70,60 & 70,77 & 71,87 & 76,93 & 75,78 \\
YOGYAKARTA & 55,15 & 57,15 & 58,91 & 64,26 & 69,73 \\
BANTEN & 62,85 & 64,33 & 65,98 & 69,95 & 69,44 \\
JAWA TIMUR & 60,60 & 62,08 & 62,55 & 68,13 & 68,19 \\
JAWA TENGAH & 55,31 & 55,84 & 58,30 & 63,74 & 64,94 \\
\hline
\end{tabular}

Tabel 1. Persentase Penduduk yang memiliki/menguasai Telpon Seluler tahun 2012-2016

Sumber: BPS Tahun 2016 (Data Diolah)

Berdasarkan data di atas, Provinsi Jawa Barat menempati urutan ke 2 setelah Provinsi DKI Jakarta dimana membuktikan bahwa penduduk Jawa Barat cukup antusias terhadap adanya trend telepon seluler. Dengan penggunaan smartphone tidak hanya digunakan untuk aksebilitas yang memungkinkan penduduk mengakses berbagai portal dan menggunakan banyak aplikasi untuk mempermudah kegiatan sehari hari mereka secara online tapi dengan kemudahan ini juga memungkinkan adanya bentuk jual beli secara virtual. Posisi ini didukung oleh data kegiatan populer penggunaan ponsel pintar di Indonesia yang diadakan oleh Deloitte tahun 2016 yang menunjukkan bahwa Indonesia merupakan konsumen terbanyak untuk hal jual beli secara virtual (Browsing shopping website and application) dibanding negara lain dalam lingkup Asia Tenggara.

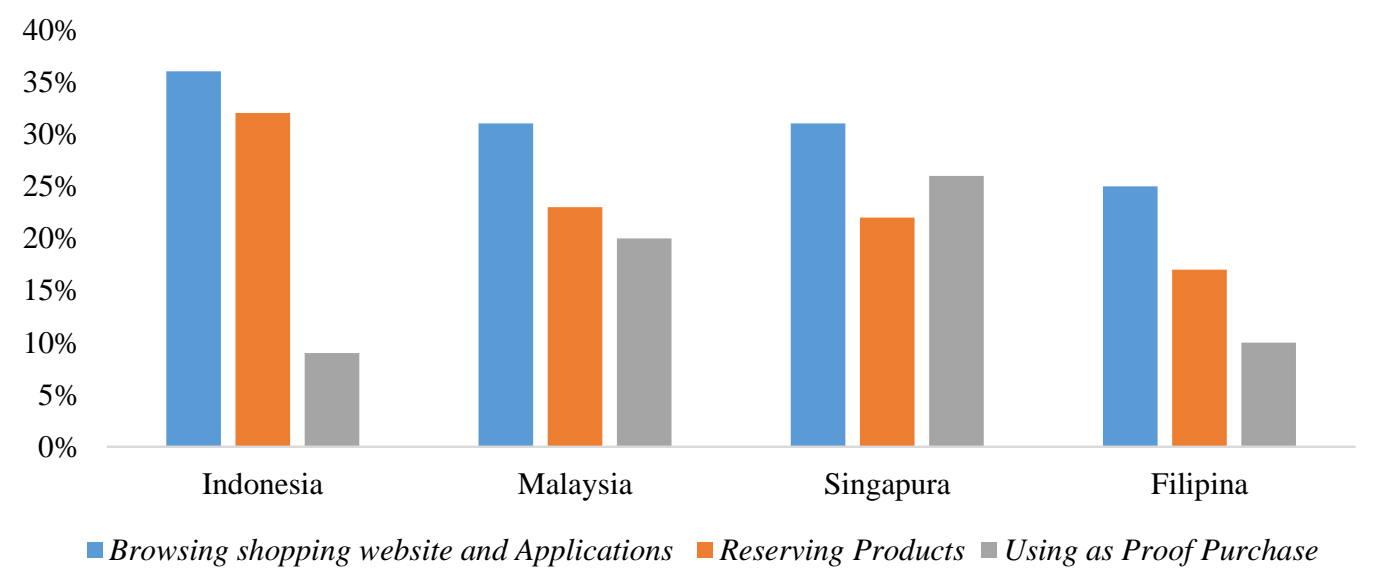

Gambar 3. Kegiatan populer penggunaan ponsel pintar Asia Tenggara Sumber: Deloitte (2017) (Data diolah)

Dengan menjadi salah satu negara dengan persentase tertinggi di Asia Tenggara dalam hal bentuk jual beli barang dan jasa secara virtual melalui perangkat ponsel pintar berbasis layanan internet (Smartphone) menjadikan kondisi ini dapat dimanfaatkan oleh perusahaan untuk membantu efektifitas dan masalah marketing sebuah perusahaan terutama dalam periklanan dan sebagai salah satu ladang bisnis yang memanfaatkan Ponsel pintar (Smartphone) dengan di luncurkannya berbagai aplikasi untuk mempermudah kegiatan transaksi secara virtual. Salah satunya adalah McDelivery Mobile Application.

McDelivery Mobile Application adalah aplikasi pemesanan makanan cepat saji berbasis franchise dari perusahaan Mcdonald's yang dikembangkan untuk membantu efektifitas pemasaran dan pemberian kemudahan dalam hal pemesanan makanan jarak jauh kepada konsumen. "McDonald's adalah restoran cepat saji yang menawarkan makanan ayam goreng dan burger khas Amerika Serikat yang ditemukan oleh Ray Kroc dan mempunyai visi untuk membuka cabang restoran ini keseluruh penjuru Amerika" (Amran, 2017). Di tingkat global, McDonald 
merupakan restoran waralaba terbesar di dunia dengan jumlah gerai sekitar 36.000, mengalahkan KFC dengan jumlah gerai sekitar 19.000 (Wibisono, 2017)

Generasi Z, yaitu generasi yang lahir pada rentang tahun 1995-2009, merupakan generasi yang sebenarnya layak disebut dengan pertama yang merupakan generasi internet (Grail Research, 2011). Generasi ini lahir ketika tekonoli internet telah tersedia, sehingga karakter mereka adalah menyukai teknologi, cenderung fleksibel, dan toleran terhadap budaya. Generasi ini cenderung tergantung pada internet dalam melakukan pencarian informasi untuk pemenuhan kebutuhan mereka, termasuk makanan dan minuman.

Rasa pengalaman dan kepuasan yang baik dari konsumen atau disebut dengan user experience diperlukan untuk mencapai target terbentuknya customer retention yaitu kondisi dimana konsumen akan menggunakan dan mengakses layanan aplikasi yang sama dimasa yang akan datang. Adanya user experience yang memuaskan akan menjadi tolak ukur berhasil tidaknya pengembangan pemasarannya dalam bidang teknologi yaitu McDelivery Mobile Application. Adanya kenaikan setiap tahun yang terjadi terkait jumlah pengguna ponsel pintar (Smartphone) dan penggunaan internet semakin membuat persaingan antar bisnis pemasaran dalam bidang teknologi untuk meningkatkan rasa kepuasan dan pengalaman yang baik yang dialami oleh konsumen salah satunya adalah McDonald's, inilah alasan urgensi mengapa permasalahan tersebut diangkat dan dilakukan penelitian dengan judul "Pengaruh User Experience Terhadap Kepuasan Konsumen Generasi Z pada Sistem Pemesanan McDelivery Mobile Application di Jawa Barat”.

\section{METODE PENELITIAN}

Metode penarikan sampel pada penelitian ini dilakukan dengan menggunakan metode nonprobability sampling dengan teknik metode snowball sampling, di mana teknik pengambilan sampel yang mula-mula jumlahnya kecil, kemudian sampel ini disuruh teman-temannya untuk dijadikan sampel (Sugiyono, 2013). Bagian awal kuesioner terdapat screening untuk memastikan kriteria pengisian kuesioner pada penelitian ini yaitu konsumen generasi $\mathrm{Z}$ yang pernah menggunakan pemesanan sistem McDelivery Mobile Application dan tinggal di daerah Jawa Barat. Ukuran responden diperoleh berdasarkan perhitungan secara matematis menggunakan rumus Slovin (Umar, 2005), yaitu:

$$
n=\frac{N}{1+N(e)^{2}}
$$

Keterangan :

$\mathrm{n} \quad=$ jumlah responden yang diambil

$\mathrm{N} \quad=$ jumlah populasi

e $\quad=$ persen kelonggaran ketidaktelitian karena kesalahan pengambilan responden yang masih dapat ditoleransi, dalam penelitian ini nilainya ditentukan sebesar 10 persen.

Populasi dalam penelitian ini adalah seluruh konsumen yang telah mengunduh aplikasi McDelivery Mobile Application dan menggunakan aplikasi McDelivery Mobile Application. Jumlah pengunduhan menurut data berjumlah sebesar 1.000.000 lebih hingga Maret 2019, namun karena perhitungan tidak bulat spesifik maka diasumsikan unduhan terbanyak yaitu 1.999.999 unduhan. Jumlah tersebut dijadikan acuan untuk digunakan sebagai populasi dalam penelitian ini.

$n=\frac{1.999 .999}{1+1.999 .999(0,1)^{2}}=99,9 \sim 100$ responden

Berdasarkan rumus di atas, maka jumlah responden yang diambil sebesar 100 responden

\section{Kerangka Pemikiran Penelitian}

McDonald's adalah salah satu perusahaan yang mengeluarkan aplikasi transaksi Application. Untuk mencapai target terbentuknya customer retention yaitu kondisi dimana konsumen akan menggunakan dan mengakses layanan aplikasi yang sama dimasa yang akan datang diperlukan adanya rasa pengalaman dan kepuasan yang baik dari konsumen atau disebut 
dengan user experience yang akan membentuk adanya kepuasan konsumen. Penelitian ini akan berfokus kepada enam dimensi daya tarik (attractiveness), kemudahan konsumen (perspicuity), efisiensi penggunaan (efficiency), ketergantungan penggunaan (dependancy), stimulasi (stimulation), dan kebaruan (novelty) terhadap kepuasan konsumen. Kerangka penelitian ini dapat dilihat pada gambar 3 .

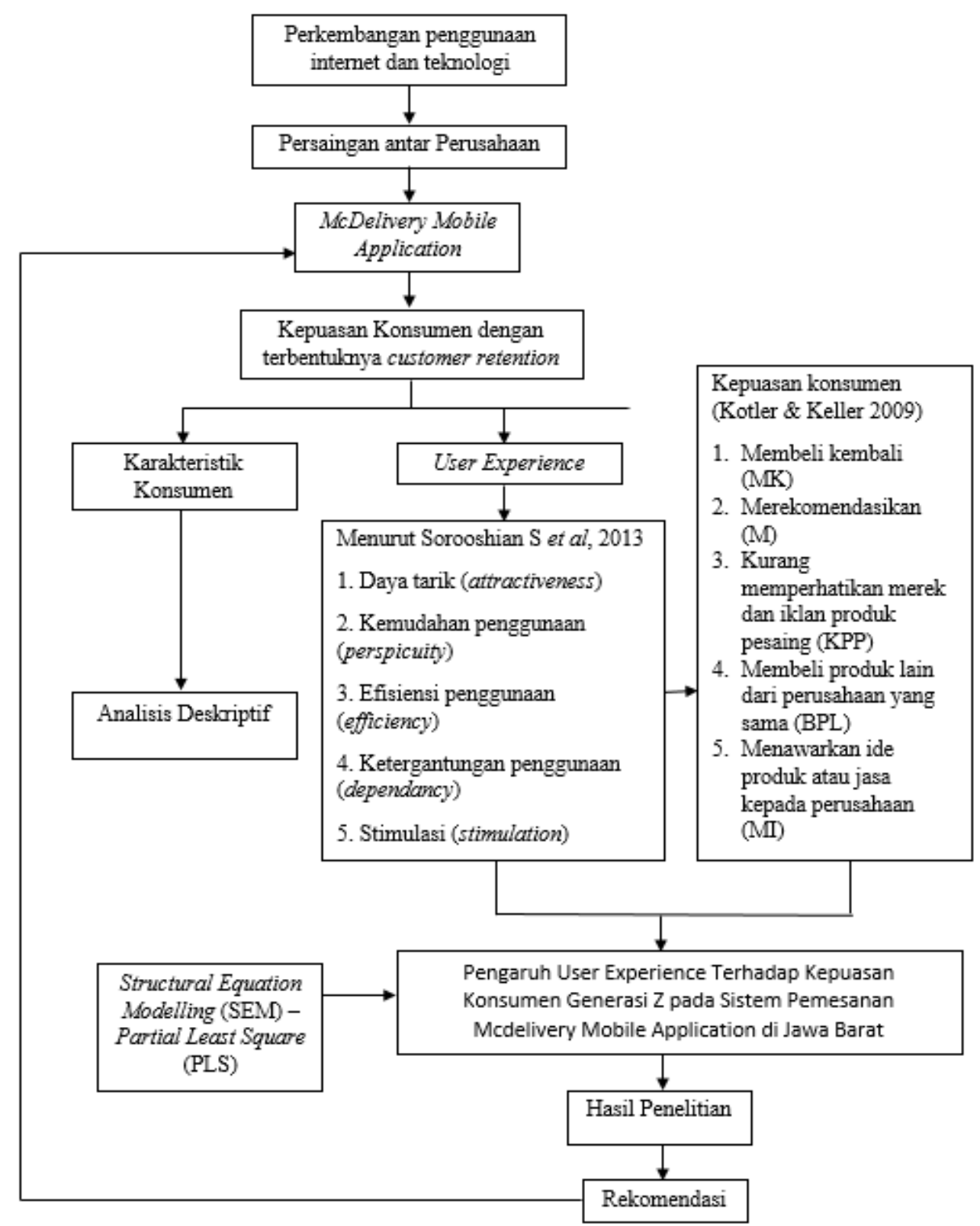

Gambar 4. Kerangka pemikiran

\section{HASIL DAN PEMBAHASAN}

\section{Analisis Structural Equation Model (SEM)}

Analisis Structural Equation Modelling (SEM) dengan menggunakan pendekatan Partial Least Square (PLS) bertujuan untuk mengetahui hubungan antar variabel-variabel laten serta variabel laten dengan indikator konstruknya. Model dibangun dengan satu variabel laten eksogen yaitu user experience dengan 30 indikator pernyataan dari enam dimensi yaitu daya tarik (DT), kemudahan konsumen (KM), efisiensi penggunaan (EP), ketergantungan penggunaan (KP), 
stimulasi (S), dan kebaruan (K) dan kepuasan, serta variabel endogen yang digunakan adalah kepuasan konsumen (KK). Pengolahan data menggunakan data primer yang didapatkan dari kuesioner yang telah diisi oleh responden berjumlah 100 orang dan analisis data menggunakan perangkat lunak SmartPLS 3.2.6.

\section{Analisis Evaluasi Pengukuran Model (Outer Model)}

Pada model awal penelitian ini, variabel laten user experience memiliki 30 pernyataan indikator yaitu DT_1, DT_2, DT_3, DT_4, DT_5, KM_1, KM_2, KM_3, KM_4, KM_5, EP_1, EP_2, EP_3, EP_4, EP_5, KP_1, KP_2, KP_3, KP_4, KP_5, S_1, S_2, S_3, S_4 , S_5, K_1, K_2, $\mathrm{K} \_3, \mathrm{~K} \_4, \mathrm{~K} \_5$, sedangkan untuk variabel laten kepuasan konsumen memiliki 5 pernyataan indikator yaitu MK, M, KPP, BPL, MI. Menurut Ghozali (2014), outer model ini menyatakan bagaimana analisis untuk menilai bagaimana setiap blok indikator berhubungan dengan variabel latennya. Suatu indikator dapat dianggap valid jika memiliki nilai convergent validity lebih besar dari 0,7 dan nilai AVE (average variance extracted reliability) di atas 0,5 sehingga berdasarkan nilai Convergent validity maka indikator DT_1, DT_2, DT_3, KM_4, KM_5, EP_2, EP_5, KP_2, KP_3, S_4, K_1, K_2, dan $\mathrm{K} \_3$ dikeluarkan karena memiliki masing-masing nilai convergent validity $<0,7$.

Proses pengeluaran (eliminasi) indikator ini dilakukan secara bertahap dan reestimasi. Indikator yang memiliki convergent validity $<0,7$ merupakan indikator kandidat untuk dieliminasi. Setiap melakukan eliminasi indikator nilai loading factor dapat berubah ketika dilakukan reestimasi. Akhirnya didapatkan model outer akhir seperti Gambar 5.

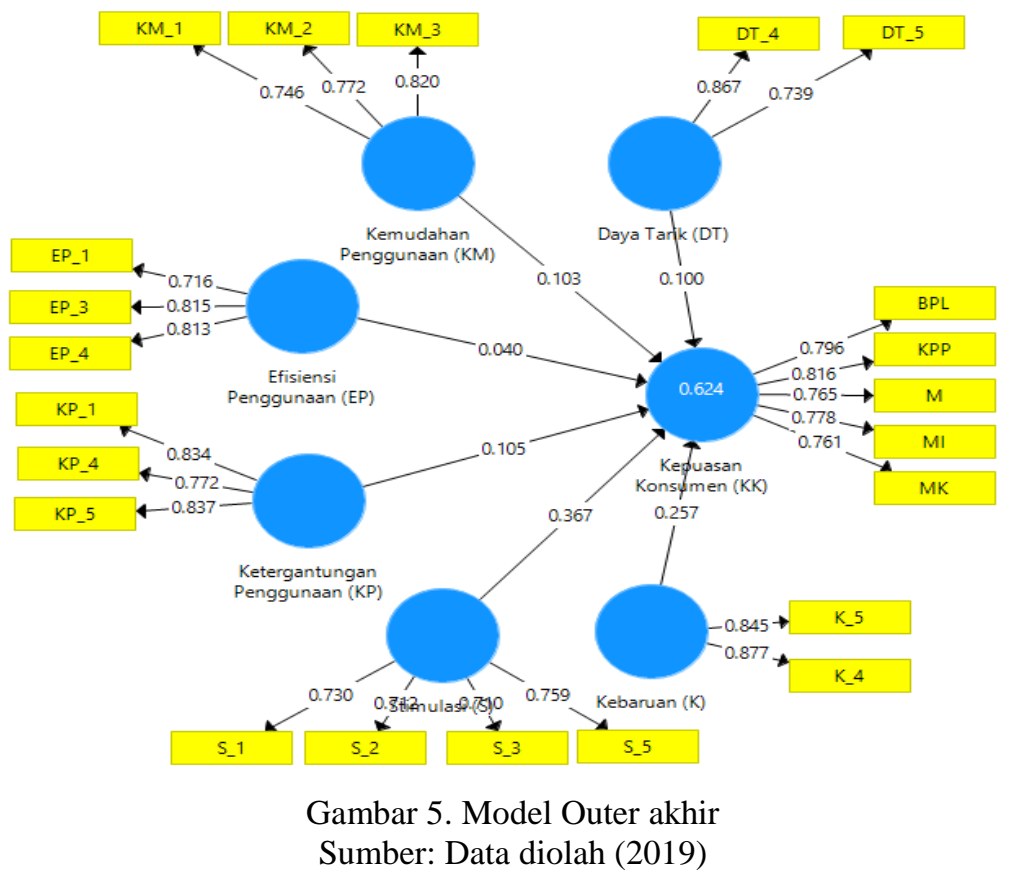

Berdasarkan Gambar 5. Pada dimensi daya tarik (attractiveness) menunjukkan DT_4 mempunyai nilai terbesar sebesar 0,867. DT_4 mempresentasikan bahwa pengguna aplikasi tertarik pada aplikasi McDelivery karena penggunaannya yang mudah dan efisien. Dimensi kemudahan konsumen (perspicuity) menunjukkan KM_3 mempunyai nilai terbesar sebesar 0,820. KM_3 mempresentasikan bahwa pengguna aplikasi bahwa Layanan "Track Orders" pada McDelivery Mobile Application membantu konsumen dalam melacak keberadaan pesanan konsumen.

Dimensi efisiensi penggunaan (efficiency) menunjukkan EP_3 mempunyai nilai terbesar pilihan pengantaran makanan bisa dengan mudah di atur pada McDelivery Mobile Application. Dimensi ketergantungan penggunaan (dependancy) menunjukkan KP_5 mempunyai nilai 
terbesar sebesar 0,837. Hal tersebut merepresentasikan KP_5 bahwa pengguna aplikasi yakin informasi dari layanan McDelivery Mobile Application sudah terjamin keamanannya.

Dimensi stimulasi (stimulation) menunjukkan S_5 mempunyai nilai terbesar sebesar 0,759. Hal tersebut merepresentasikan S_5 bahwa adanya iklan menu baru pada McDelivery Mobile Application memungkinkan konsumen bisa memesan makanan dengan segera pada dimensi stimulasi (stimulation). Dimensi kebaruan (novelty) menunjukkan K_4 mempunyai nilai terbesar sebesar 0,877. Hal tersebut merepresentasikan K_4 bahwa sistem pemesanan makanan padaMcDelivery Mobile Application adalah contoh aplikasi dengan fitur lengkap.

Variabel kepuasan konsumen menunjukkan KPP mempunyai nilai terbesar sebesar 0,816. Hal tersebut merepresentasikan KPP bahwa pengguna merasa puas dengan sistem pemesanan makanan pada McDelivery Mobile Application, dan akan merekomendasikan kepada calon pengguna lain. Tahap kedua evaluasi, yaitu discriminant validity dengan melihat nilai average variance extraxted (AVE). Syarat model memiliki validitas yang baik apabila masing-masing variabel laten memiliki nilai AVE lebih besar dari 0,5. Nilai AVE dapat dilihat pada Tabel 2.

Tabel 2. Nilai Average Variance Extraxted (AVE)

\begin{tabular}{lcc}
\hline \multicolumn{1}{c}{ Variabel Laten } & AVE & Keterangan \\
\hline Kepuasaan Konsumen & 0,614 & Valid \\
Ketergantungan Penggunaan & 0,664 & Valid \\
Stimulasi & 0,530 & Valid \\
Efisiensi Penggunaan & 0,613 & Valid \\
Kemudahan konsumen & 0,608 & Valid \\
Kebaruan & 0,742 & Valid \\
Daya Tarik & 0,649 & Valid \\
\hline
\end{tabular}

Sumber: Data diolah (2019)

Berdasarkan nilai AVE pada Tabel 2 terlihat bahwa seluruh variabel laten telah memenuhi uji validitas karena nilai AVE lebih besar dari 0,5 (Ghozali, 2014). Setelah semua variabel dinyatakan valid, selanjutnya dilakukan pengukuran nilai reabilitas dengan melihat nilai composite reability dan cronbach alpha.

Tabel 3. Nilai Composite Reliability and Cronbach's Alpha

\begin{tabular}{lcc}
\hline \multicolumn{1}{c}{ Variabel Laten } & Composite Reliability & Cronbach's Alpha \\
\hline Kepuasaan Konsumen & 0,888 & 0,843 \\
Ketergantungan Penggunaan & 0,855 & 0,747 \\
Stimulasi & 0,818 & 0,706 \\
Efisiensi Penggunaan & 0,825 & 0,687 \\
Kemudahan konsumen & 0,823 & 0,678 \\
Kebaruan & 0,852 & 0,653 \\
Daya Tarik & 0,786 & 0,468 \\
\hline
\end{tabular}

Sumber: Data diolah (2019)

Berdasarkan Tabel 3 bahwa 7 variabel laten memiliki nilai lebih dari 0,70 untuk composite reability dan enam variabel laten memiliki nilai lebih dari 0,6 untuk cronbach alpha (Ghozali, 2014), sehingga dapat disimpulkan bahwa semua konstruk memiliki reliabilitas yang baik kecuali variabel daya tarik untuk dibagian cronbach alpha.

\section{Analisis Evaluasi Model Struktural (Inner Model)}

Evaluasi model struktural (inner model) digunakan untuk menguji pengaruh antara satu variabel laten dengan variabel laten lainnya baik eksogen maupun endogen, apakah terdapat pengaruh positif atau negatif. Pengujian dilakukan dengan melihat output SmartPLS dari nilai bootstrapping antar variabel. Pengaruh variabel independen secara keseluruhan terhadap variabel dependen dapat dilihat dari nilai $R$-square (R2). Nilai $R$-square digunakan untuk menjelaskan variabel laten eksogen tertentu terhadap variabel 1 aten endogen. Nilai $R$-square pada setiap model dapat dilihat pada Tabel 4. 
Tabel 4. Nilai $R$-Square

\begin{tabular}{lc}
\hline Variabel Laten & $R$-Square \\
\hline Kepuasaan Konsumen & 0,624 \\
\hline Sumber: Data diolah (2019) &
\end{tabular}

Inner model dievaluasi dengan melihat nilai $R$-square untuk menjelaskan variabel laten eksogen terhadap variabel laten endogen. Berdasarkan hasil perhitungan SEM-PLS, model pengaruh user experience terhadap kepuasan konsumen memberikan nilai $R$-square sebesar 0,624 yang dapat diinterpretasikan bahwa variabel kepuasan konsumen dapat dijelaskan oleh user experience sebesar 62,4 persen, sedangkan 37,6 persen dijelaskan oleh variabel lain yang tidak diteliti dalam penelitian ini.

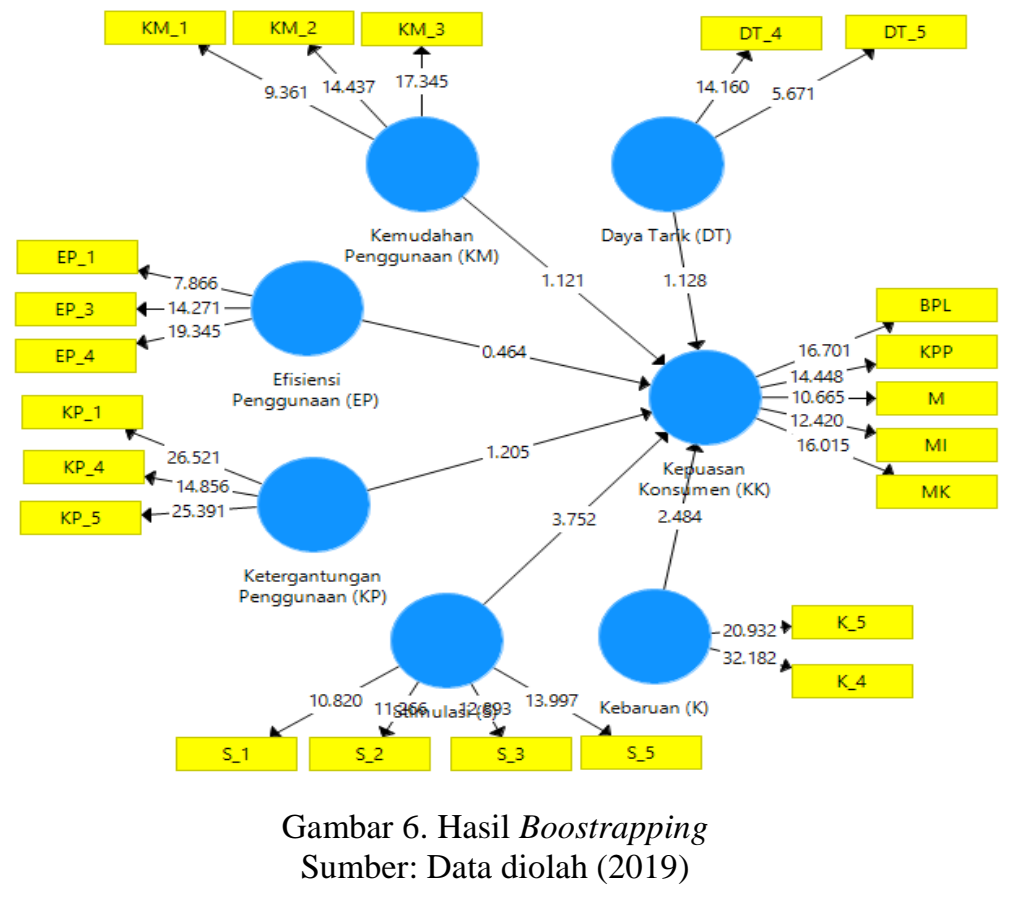

Nilai t-statistik menunjukkan signifikansi variabel, sedangkan nilai original sample menunjukkan sifat hubungan antar variabel (positif atau negatif). Kriteria pengujian untuk variabel laten eksogen berpengaruh terhadap variabel laten endogen apabila t-hitung $>$ t-tabel dengan nilai t-tabel sebesar 1,96 pada taraf nyata 0,05 .

Tabel 5. Nilai Path Coefficient

\begin{tabular}{lccl}
\hline Hipotesis & $\begin{array}{c}\text { Original } \\
\text { Sample }\end{array}$ & t-statistik & keterangan \\
\hline Daya Tarik -> Kepuasaan Konsumen & 0,100 & 1,161 & $\begin{array}{l}\text { Positif Tidak } \\
\text { Signifikan }\end{array}$ \\
Efisiensi Penggunaan-> Kepuasaan Konsumen & 0,040 & 0,456 & $\begin{array}{l}\text { Positif Tidak } \\
\text { Signifikan }\end{array}$ \\
Kebaruan -> Kepuasaan Konsumen & 0,257 & 2,612 & $\begin{array}{l}\text { Positif } \\
\text { Signifikan }\end{array}$ \\
Kemudahan konsumen-> Kepuasaan Konsumen & 0,103 & 1,191 & $\begin{array}{l}\text { Positif Tidak } \\
\text { Signifikan }\end{array}$ \\
Ketergantungan Penggunaan -> Kepuasaan Konsumen & 0,105 & 1,212 & $\begin{array}{l}\text { Positif Tidak } \\
\text { Signifikan }\end{array}$ \\
Stimulasi -> Kepuasaan Konsumen & 0,367 & 3,903 & $\begin{array}{l}\text { Positif } \\
\text { Signifikan }\end{array}$ \\
\hline
\end{tabular}

Sumber: Data diolah (2019)

Tabel 5 menunjukkan bahwa daya tarik tidak berpengaruh signifikan terhadap variabel kepuasan konsumen dengan T-statistik sebesar 1,161 $(<1,96)$ dengan nilai original sample adalah 
positif, yaitu sebesar 0,100 yang menunjukkan bahwa arah hubungan antara daya tarik dengan kepuasan konsumen adalah positif. Efisiensi penggunaan tidak berpengaruh signifikan terhadap variabel kepuasan konsumen dengan T-statistik sebesar $0,456(<1,96)$ dengan nilai original sample adalah positif, yaitu sebesar 0.040 yang menunjukkan bahwa arah hubungan antara efisiensi penggunaan dengan kepuasan konsumen adalah positif.

Kebaruan berpengaruh signifikan terhadap variabel kepuasan konsumen dengan T-statistik sebesar 2,612 (>1,96) dengan nilai original sample adalah positif, yaitu sebesar 0,257 yang menunjukkan bahwa arah hubungan antara kebaruan dengan kepuasan konsumen adalah positif. Kemudahan konsumen tidak berpengaruh signifikan terhadap variabel kepuasan konsumen dengan T-statistik sebesar 1,191 (<1,96). Nilai original sample adalah positif, yaitu sebesar 0,103 yang menunjukkan bahwa arah hubungan antara kemudahan konsumen dengan kepuasan konsumen adalah positif.

Ketergantungan penggunaan tidak berpengaruh signifikan terhadap variabel kepuasan konsumen dengan T-statistik sebesar 1,212 $(<1,96)$ dengan nilai original sample adalah positif, yaitu sebesar 0,105 yang menunjukkan bahwa arah hubungan antara ketergantungan penggunaan dengan kepuasan konsumen adalah positif. Stimulasi berpengaruh signifikan terhadap variabel kepuasan konsumen dengan T-statistik sebesar 3,903 (>1,96). Nilai original sample adalah positif, yaitu sebesar 0,367 yang menunjukkan bahwa arah hubungan antara stimulasi dengan kepuasan konsumen adalah positif.

Total dari semua variabel user experience diketahui hanya dua variabel yang mempengaruhi kepuasan konsumen dengan positif dan signifikan, yaitu variabel kebaruan dan variabel stimulasi dengan nilai T-statistik masing-masing 2,612 dan 3,903 (>1,96) dengan nilai original sample adalah positif, yaitu sebesar 0,257 dan 0,367 yang menunjukkan bahwa arah hubungan antara kebaruan dan stimulasi dengan kepuasan konsumen adalah positif.

\section{Implikasi Manajerial}

Kim dan Mauborgne (2005), menyatakan bahwa terdapat empat kerangka kerja yang terdiri dari ciptakan (create), kurangi (reduce), hapuskan (eliminate), dan tingkatkan (raise). Munandar et al. (2014) dalam pendekatan fungsional menyatakan implikasi manajerial berkaitan dengan fungsi manajemen. manajemen dibedakan dalam empat hal, yaitu planning (perencanaan), organizing (pengorganisasian), leading (kepemimpinan), dan controlling (pengawasan). Adanya pengaruh user experience terhadap kepuasan pada aplikasi McDelivery Mobile Application dapat dijadikan acuan untuk meningkatkan kualitas aplikasi serta pelayanannya terhadap pengguna. Implikasi manajerial dari penerapan Blue Ocean Strategy aplikasi McDelivery Mobile Application terhadap planning, organizing, leading dan controlling sebagai berikut:

1. Perencanaan yang dapat dilakukan perusahaan McDonalds jika dilihat dari dimensi kebaruan yang berpengaruh positif terhadap variabel kepuasan konsumen, pihak perusahaan dapat memperbaharui sistem pembayaran dengan sistem online agar mempermudah saat sistem transaksi, kemudian melakukan penambahan terkait adanya inovasi fitur baru dengan memperjelas keberadaan pesanan melalui GPS agar konsumen bisa bersiap saat pengantaran, juga melakukan promosi di gerai secara langsung dengan memberikan keterangan tentang adanya aplikasi dengan mencantumkan berbagai keunggulan dan promo yang ditawarkan sehingga penambahan konsumen dari aplikasi akan bertambah.

2. Pengelompokkan yang dapat dilakukan perusahaan McDonalds dengan melihat skor tanggapan responden paling rendah pada pernyataan kemudahan konsumen (KM) yaitu pernyataan (KM_4) "Pilihan menu pesanan pada McDelivery Mobile Application memudahkan konsumen dalam menemukan menu yang diinginkan", maka perusahaan harus mengatur kembali tampilan menu dan urutan pemesanan agar mudah di gunakan juga memberikan fitur search pada tampilan menu agar menu yang diinginkan bisa langsung di cari pada kolom pencarian, hal ini terkait dalam fungsi pengelompokkan agar tampilan semakin teratur dan kedepannya lebih memudahkan konsumen. 
3. Pengarahan yang dapat dilakukan perusahaan McDonalds adalah penempatan rekomendasi rekomendasi menu pilihan juga pengarahan tentang cara pemakaian aplikasi dengan membuat instruksi baru di web resmi serta ditampilkan secara langsung pada aplikasi yang lebih simpel dan memudahkan pengguna aplikasi, juga pengarahan terkait melakukan pembagian tugas yang cukup jelas serta mengkoordinasikannya sehingga akan mempersingkat waktu karyawan dalam menanggapi pemesanan. Pengarahan menegenai penambahan jumlah karyawan pada saat jam ramai sebaiknya dilakukan agar dapat mengurangi waktu tunggu pelanggan.

4. Pengendalian yang dapat dilakukan oleh perusahaan McDonalds yaitu memantau banyaknya pengunduh dan jumlah pesanan pada aplikasi juga meninjau dan mempertahankab kebaruan yang dimiliki dan tetap melakukan stimulasi agar lebih memuaskan konsumen.

\section{KESIMPULAN}

Berdasarkan hasil analisis, dapat disimpulkan bahwa masing-masing variabel independen (Personal Relevance, Interactivity, Message, Brand Familiarity) secara serentak dan bersamasama berpengaruh secara signifikan terhadap Keputusan Pembelian. Selanjutnya, dari hasil analisis juga dapat dinyatakan bahwa variabel Interactivity, Message, dan Brand Familiarity secara parsial berpengaruh positif dan signifikan terhadap Keputusan Pembelian. Hal ini menunjukan apabila terjadi peningkatan pada nilai variabel Interactivity, Message, dan Brand Familiarity, maka akan semakin mempengaruhi Keputusan Pembelian secara signifikan. Sedangkan variabel Personal Relevance tidak berpengaruh secara signifikan terhadap Keputusan Pembelian.Variabel yang dominan berpengaruh terhadap Keputusan Pembelian adalah variabel Interactivity. Hal ini menunjukkan apabila nilai variabel Interactivity ditingkatkan, maka keputusan pembelian akan mengalami peningkatan yang lebih signifikan apabila dibandingkan dengan variabel lainnya.

\section{DAFTAR PUSTAKA}

Amran, F. R. (2017). Analisis Strategi Bisnis Mcdonald's Di Labuhan Ratu [Skripsi]. Lampung: Universitas Lampung.

[APJII] Asosiasi Penyelenggara Jasa Internet Indonesia. 2016. Profil Pengguna Internet Indonesia. Jakarta: Asosiasi Penyelenggara Jasa Internet Indonesia.

[APJII] Asosiasi Penyelenggara Jasa Internet Indonesia. 2017. Komposisi Pengguna Internet Indonesia Berdasarkan usia. Jakarta: Asosiasi Penyelenggara Jasa Internet Indonesia.

Ghozali, I. 2014. Structural Equation Modeling Metode Alternatif dengan Partial Least Square (PLS) Dilengkapi Software Smartpls 3.0. Xlstat 2014 danm WarPLS 4.0. Yogyakarta (ID): Badan Penerbit Universitas Diponegoro.

Grail Research. 2011. Consumers of Tomorrow Insights and Observations About Generation Z. Diakses dari http://www. integreon.com/pdf/Blog/Consume rs_of_Tomorrow_Insights_and_O bservations_About_Generation_Z_246.pdf.

[Katadata]. Kata data. Pengguna smartphone di Indonesia 2016-2019. [internet]. [diunduh 2019 Mar 9]. Tersedia pada : https://databoks.katadata.co.id/datapublish/2016/08/08/pengguna-smartphone-diindonesia-2016-2019.

Kim, W. C., \& Mauborgne, R. (2005). Blue Ocean Strategy. Boston: Harvard Business School.

Munandar, J. M., Kartika, L., Permanasari, Y., Indrawan, R. D., Andrianto, M. S., \& Siregar, E. (2014). Pengantar Manajemen. Bogor: PT Penerbit IPB Press.

Sugiyono. (2013). Metode Penelitian Pendidikan Pendekatan Kuantitatif, Kualitatif, dan R\&D. Bandung: Alfabeta.

Umar, H. (2005). Metode Penelitian. Jakarta: Salemba Empat.

Wibisono, N. (2017). Persaingan KFC vs McDonald's di Indonesia. Tirto.id. Diakses dari https://tirto.id/persaingan-kfc-vs-mcdonalds-di-indonesia-chbu. 